\title{
ИНОЯЗЫЧНЫЕ ВКРАПЛЕНИЯ ПОЛЬСКОГО ПРОИСХОЖДЕНИЯ В ЛЕКСИКЕ РУССКОГО ЯЗЫКА (ОБЩИЕ ПОЛОЖЕНИЯ)
}

LUKÁŠ PLESNÍK

\section{FOREIGN LANGUAGE INCLUSIONS OF POLISH ORIGIN IN THE VOCABULARY OF THE RUSSIAN LANGUAGE (GENERAL POSITIONS)}

ABSTRACT The article focused on the issue of foreign language inclusions of Polish origin in the vocabulary of the Russian language. Attention is paid to the most important terms of the topic under study (borrowing, foreign language inclusion, polonism, source language, intermediary language). Based on the compiled database of linguistic data is presented an analysis focused on temporal aspect of foreign language inclusions of Polish origin and an analysis focused on part of speech aspect offoreign language inclusions of Polish origin.

KEY WORDS foreign language inclusion, borrowing, language contact, polonism, intermediary language, source language, temporal analysis, part of speech analysis, Polish language, Russian language

CONTACT Ostravská univerzita, Filozofická fakulta, Katedra slavistiky;

lukas.plesnik@osu.cz 
Заимствование представляет собой один из главнейших процессов обогащения словарного состава любого языка. Сам процесс упоминается в научной литературе, главным образом, в связи с заимствованием иноязычных лексических единиц, особенно или из классических языков (древнегреческий и латинский языки), или из западноевропейских языков (немецкий, французский, английский языки). Общеизвестно, что в словарном составе русского языка встречаются также слова, относящиеся к языкам, не играющим в процессе заимствования такой выразительной роли. А именно такого рода высказывание можно использовать относительно польского языка.

Феномен процесса заимствования неоднократно отмечается в многочисленных лингвистических словарях русского языка. К примеру, Словарь лингвистических терминов О. С. Ахмановой определяет заимствование как «обращение к лексическому фонду других языков для выражения новых понятий, дальнейшей дифференциации уже имеющихся и обозначения неизвестных прежде предметов» (Ахманова 1966 (2016): 150). Дополняя данное определение, автор уточняет, что «нередко сами эти понятия и предметы становятся известными носителям данного языка лишь вследствие контактов с теми народами, из чьих языков заимствуются соответствующие слова» (Ахманова 1966 (2016): 150-151). Аналогичные определения дают также современные лингвистические словари, например, Энщиклопедический словарь-справочниклингвистических терминов и понятий. Русский язык под общей редакцией А. Н. Тихонова и Р. И. Хашимова, толкующий заимствование как «процесс вхождения иноязычных элементов в тот или иной язык для выражения новых понятий, реалий или дальнейшей дифференциации исконных полисемантичных слов в результате языковых контактов» (Тихонов, Хашимов 2008: 59). Наряду с заимствованием, как процессом приобретения языком-реципиентом иноязычных элементов языка-источника, следует выделить заимствования в смысле реальных лексических единиц. Итак, заимствования - «слова, словообразовательные аффиксы и конструкции, вошедшие в данный язык в результате заимствования (в первом значении)» (Ахманова 1966 (2016): 151). Фактически тождественное определение дает также второй нами упоминаемый источник: заимствования - «языковые конструкции, модели и единицы, преимущественно слова, вошедшие в данный язык в результате заимствования» (Тихонов, Хашимов 2008: 59).

Ссылаясь на отмеченные выше определения, очевидно, что как процесс заимствования, так и его результат в форме заимствований, т. е. заимствованных слов, неотъемлемо связаны со взаимодействием языковых контактов. Как отмечает К. С. Захватаева, «в настоящее время не вызывает сомнения тот факт, что на протяжении своего исторического развития различные общности, коллективы людей и целые нации вступают между собой в те или иные контакты - культурные, политические, экономические, военные и другие. Однако все они обязательно подразумевают параллелизм языковых контактов» (Захватаева 2010: 165). В современной лингвистике изучению языковых контактов уделяется особое внимание, хотя сам термин языковой контакт вызывает неоднозначные реакции и толковать его можно по-разному ${ }^{1}$. Согласно Словарю лингвистических

1 Термин языковой контакт был определен в российском языкознании Л. Н. Щербой, основополагающий термин «langue(s) en contact» был предложен французским лингвистом А. Мартине. В широкое употребление был введен лингвистом У. Вайнрайхом, заменив первоначальный термин 
терминов О. С. Ахмановой, языковой контакт - «соприкосновение языков, возникающее вследствие особых географических, исторических и социальных условий, приводящих к необходимости языкового общения человеческих коллективов, говорящих на разных языках» (Ахманова 1966 (2016): 535). Таким образом, языковые контакты можно считать взаимодействием двух или более языков в процессе общения языковых групп, вступающих в разного рода связи и отношения. Вследствие того лингвистические результаты языковых контактов различны. Среди них преобладают, прежде всего, языковые заимствования, явления интерференции и смешение языков, результаты которых могут дойти до формирования различных видов билингвизма или даже смены языка (Жеребило 2010: 482). Языковые заимствования, воспринимающиеся как результат взаимодействия языковых контактов, также можно определить с помощью термина иноязычные вкрапления.

Вкрапление, в общем смысле слова, представляет собой использование языковой единицы с сохранением фонетических или грамматических признаков, указывающих на ее иносистемный характер. Вкрапление можно рассматривать как внешнее, так внутреннее. Под внешним вкраплением понимается вкрапление иностранного слова, внутреннее вкрапление - включение диалектного или просторечного слова (Жеребило 2010: 60). Термин иноязычное вкрапление ${ }^{2}$ опирается на понятие варваризм, со значением которого его определение тесно связано. По мнению Л. П. Крысина, иноязычные вкрапления - это «незамкнутые группы слов, употребление которых обусловлено степенью знакомства говорящего с иностранным языком, некоторыми стилистическими или жанровыми особенностями речи» (Крысин 1968: 47, Норлусенян 2010: 63). В дальнейшем проблематикой иноязычных вкраплений занимались В. С. Гимпелевич, Н. А. Еремия или С. Влахов и С. Флорин, понимающие под иноязычными вкраплениями «слова и выражения на чужом для подлинника языке, в иноязычном их написании или транскрибированные без морфологических или синтаксических изменений, введенные автором для придания тексту аутентичности, для создания колорита, атмосферы или впечатления начитанности или учености, иногда - оттенка комичности или иронии» (Влахов, Флорин 1980: 263, Норлусенян 2010: 64). Согласно В. С. Норлусеняну, важной проблемой функционирования иноязычных вкраплений на современном этапе развития языка является их адаптация в тексте. Автор выделяет два способа ввода иноязычных вкраплений. Первый способ - иноязычное слово, вводимое впервые в речевой обиход языка-реципиента, воспроизводится без какой-либо заметки, примечания и т. п.; второй способ - иноязычное слово сопровождается определенными авторскими комментариями или примечаниями (Норлусенян 2010: 65). Выбор подходящего способа зависит

Г. Шухардта смешение языков. На современном этапе можно выделить отдельное лингвистическое направление, называемое контактной лингвистикой, лингвистикой языковых контактов или лингвистической контактологией (Захватаева 2010: 165-170, Рогозная 2014: 306-311).

2 Впервые термин иноязычное вкрапление упоминается в статье Иноязычные вкрапления в русскую речь А. А. Леонтьева. В данной работе автор классифицирует внесистемные иноязычные элементы, относив к ним и русские слова, употребляемые с нарушением их семантики и в нерусском звуковом оформлении, и русские слова со своей семантикой и звуковым оформлением, употребляемые в иноязычной грамматической форме или с нарушением русской грамматической формы (Леонтьев 1966: 60-68, Норлусенян 2010: 63-66). 
от намерений автора, читательской аудитории и, не в последнюю очередь, от структуры и представляемой автором темы.

Сравнительно немалую группу описанных выше иноязычных элементов образуют в лексике русского языка иноязычные вкрапления польского происхождения ${ }^{3}$. Такого рода лексические единицы принято называть полонизмами. Полонизм - это лексическая единица, заимствованная из польского языка. Согласно Н. М. Шанскому, слова из польского языка попадали в русский язык в основном в XVI-XVII вв., и прежде всего с голоса, т. е. не в письменной форме, как в случае ряда слов других языков-источников (древнегреческий или латинский языки). Н. М. Шанский одновременно отмечает, что полонизмы, как правило, являются бытовыми наименованиями, к числу которых можно отнести выражения типа бляха, булка, вензель, зразы, карета, кофбта, панцирь, сбруя, фбуражка, иирюльник и др. (Шанский 1964 (2017): 110). Объяснение термину полонизм дают также русские толковые словари. Толковый словарь русского языка С. И. Ожегова и Н. Ю. Шведовой определяет понятие полонизм как «слово или оборот речи в каком-нибудь языке, заимствованные из польского языка или созданные по образцу польского слова или выражения» (Ожегов, Шведова 2017: 532). Аналогичное определение, ссылающееся одновременно на термин варваризм, указывает Толковый словарь русского языка под редакцией Д. Н. Ушакова. Данный источник определяет термин полонизм как «вид варваризма - оборот речи, выражение в каком-нибудь языке, составленное по образцу польского языка» (Ушаков 1935-1940).

Рассматривая иноязычные вкрапления польского происхождения в лексике русского языка, необходимо подчеркнуть посредническую роль польского языка в обогащении русского литературного языка. Польский язык на протяжении веков выступал не так активно в роли языка-источника, а скорее всего он выполнял роль языка-посредника, т. е. роль контактного языка4. Понятие язык-посредник можно рассматривать с двух основных точек зрения. С одной стороны, язык-посредник представляет собой любой вспомогательный (неродной) язык, используемый в межнациональной коммуникации, с другой стороны, язык-посредник - это набор правил, в соответствии с которыми характеристики одного языка преобразуются в характеристики другого языка (Тихонов, Хашимов 2008: 238-239). Однако, несмотря на сильную позицию роли польского языка как языка-посредника (ср. бант (< польск. bant<нем. Band), бунт (< польск. bunt $<$ нем. Bunt), канцелярия (< польск. kancelaria < лат. cancellaria), конкурс (< польск. konkurs < лат. concursus), лектор (< польск. lektor < нем. Lektor < лат. lector), манера (< польск. maniera

3 Проблематике иноязычных вкраплений польского происхождения посвящен ряд исследований, к примеру, научные труды Я. К. Грота, А. И. Соболевского, Н. С. Трубецкого, В. В. Виноградова, Л. А. Булаховского, Л. А. Войновой, Л. Л. Кутиной, Л. П. Крысина и других языковедов (Гадимова 2019: 98).

4 Понятие контактный язык можно воспринимать в более широком диапазоне. С одной стороны, как вспомогательный язык, возникающий в условиях отсутствия других способов межэтнической коммуникации (смешанный язык (препиджин), пиджин, креольский язык), или, с другой стороны, как язык-посредник, выполняющий посредническую роль в процессе заимствования иноязычных элементов. Сам контакт в процессе заимствования может осуществляться прямо (вхождение слова в язык-реципиент непосредственно из языка-источника), или опосредованно (вхождение слова в язык-реципиент через язык-посредник). Именно такую роль сыграл польский язык в процессе заимствования многочисленных лексических единиц в лексику русского языка. 
$<$ франи. manière), пориия (< польск. рогсја < лат. portio), panopm (< польск. raport < фррани. rapport), mpaкm (< польск. trakt<нем. Trakt<лат. tractus), шпик (< польск. szpik / śpik<нем. Speck) и др.), в лексике русского языка можно выделить также группу слов, относящуюся непосредственно к польскому языку как языку-источнику (ср. aucm (< польск. hajster), вензель (< польск. wе̨zең), мазурка (< польск. таzurek), пан (< польск. рап), повидло (< польск. powidto), полковник (< польск. putkownik), nотрафбить (< польск. potrafić), сейм (< польск. sejm), смак (< польск. smak), хоругвь (< польск. choragiew) и др.).

Значительное положение польского языка в роли языка-посредника (и также языка-источника) многочисленных заимствований доказывает одновременно взаимное историческое контактирование русского и польского языков. Взаимотношения обоих языков осуществлялись на фоне геополитического пространства бывших держав, т. е. Российской империи и Речи Посполитой (позже Царства Польского), а то именно в связи с выразительными историческими и социальными условиями общения обоих народов, проживающих на данной территории.

Допетровская эпоха, период правления царя Петра I и вообще первая половина XVIII в. относительно иноязычных вкраплений польского происхождения характеризуются, главным образом, ролью польского языка как языка-посредника (ср. агония, бутылка, капрал, кухарка, рекрут и др.). К числу важнейших исторических событий можно отнести три раздела территории Речи Посполитой в течение второй половины XVIII в. (1772 г., 1793 г., 1795 г.), послуживших причиной появления и расширения многих полонизмов в русском языке. В связи с созданной геополитической ситуацией постепенно росло участие россиян в общественной, экономической и культурной жизни Царства Польского, слова польского речевого обихода интенсивно использовались в речи русскоговорящих, внедряясь, таким образом, в лексику русского языка. Сравнительно большое влияние на лексический фонд русского языка оказало также Польское восстание 1863 г., вошедшее в историю одновременно под названием Январское восстание. Целью данного исторического события было восстановление Речи Посполитой в границах 1772 г. (ср. полонизмы типа жонд, повстанец, фасовать, хоругвь, шинкарь и др.). Среди важных обстоятельств XX века, которые повлияли на заимствования польского происхождения в русском языке, следует подчеркнуть межвоенный период и годы совместной борьбы против фашизма (ср. полонизмы типа комплекция, претензия, регламент, станция, фбольга).

Фактический материал настоящей статьи составлен с помощью выборки иноязычных вкраплений польского происхождения. Источником для составления базы языковых данных и последующего анализа послужил Больщой этимологический словарь русского языка М. В. Климовой (2016). Методом сплошной выборки была составлена база языковых данных, насчитывающая 240 лексических единиц, для которых считается польский язык или непосредственным языком-источником, или в рамках этимологического пути определенного слова выступает в роли языка-посредника. Представленный ниже анализ базируется на временном аспекте процесса заимствования и отражает частеречную принадлежность польскоязычных вкраплений в лексике русского языка.

Анализ, опирающийся на временной аспект иноязычных вкраплений польского происхождения, указывает на факт, что полонизмы входили в лексику русского языка постепенно на протяжении многих веков (IX-XXI вв.). Из общего количества 
240 полонизмов мы определили век, в течение которого данная лексическая единица была, по всей вероятности, заимтвована русским языком. Лишь в случае пяти выражений источник не указывает, когда полонизм проник в лексику русского языка (cp. aucm, компания, литер, шмат, шабаш). Временной аспект иноязычных вкраплений польского происхождения иллюстрирует диаграмма № 1 (см. ниже).

Диаграмма № 1

Временной аспект иноязычных вкраплений польского происхождения (собственный источник автора)

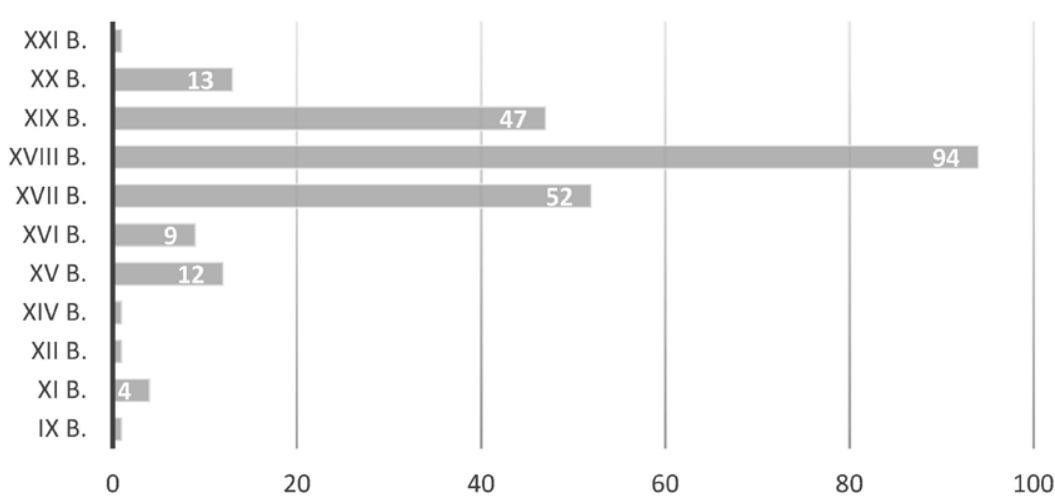

На основе нами созданной базы языковых данных можно отметить, что самые первые заимствования польского языка в русском языке относятся еще к периоду до XIV в. Количество польскоязычных вкраплений периода IX-XIV вв. невелико, к данному периоду относятся единичные случаи заимствований (ср. темляк (IX в.), укроп (XI в.), монета (XII в.), рама (XIV в.) и др.).

Период XV-XVI вв. выделяется небольшим увеличением количества полонизмов в лексике русского языка. Большинство заимствований данного периода этимологически относится к другим языкам-источникам, польский язык выступает в преобладающем ряде случаев в роли языка-посредника (ср. атлас, таблии, тракт, холера, иукат (XV в.), башня, объект, палитра, поэзия, юбка (XVI в.) и др.). К числу полонизмов, относящихся этимологически непосредственно к польскому языку, можно отнести выражения заядлый или пан (XVI в.).

Период XVII-XIX вв. характерен большим притоком вкраплений польского происхождения. Самое высокое количество полонизмов внедрилось в лексику русского языка в XVIII в., по нашим данным к определенному времени относятся всего 94 польскоязычных вкрапления (ср. бант, бекеша, гусар, забияка, козырь, крахмал, мускул, опека, реестр, фалда и др.). К периоду XVII и XIX вв. относится сравнительно сходное количество вкраплений, однако по сравнению с количеством вкраплений XVIII в. их почти в два раза меньше. На основе базы языковых данных русский язык заимствовал в XVII в. 52 полонизма (ср. баталия, белизна, гвардия, замша, кролик, куртка, мещанин, паралич, позволить, 
разруха и др.), в XIX в. - 47 полонизмов (ср. бастовать, бричка, луза, механик, публичныци, реляция, фальшь, фортель, характеристика, шинкарь и др.). Следует отметить, что среди заимствованных лексических единиц встречаются польскоязычные вкрапления, для которых является польский язык как языком-посредником (ср. бунт, канщелярия, курьер, мануфбактура, проблема и др.), так и языком-источником (ср. вензель, доскональный, зразы, малевать, подлый и др.).

Период XX-XXI вв. отличается лишь небольшим количеством новых польскоязычных заимствований в лексике русского языка. К периоду XX в. можно отнести 13 полонизмов (ср. комплекция, претензия, регламент, станция, терминология и др.), к XXI в. относит база языковых данных всего одну лексическую единицу - лексему шпонка, происходящую от немецкого выражения Spon, вошедшую в русский язык через польское выражение szponka.

Анализ, указывающий на частеречный аспект иноязычных вкраплений польского происхождения в русском языке, указывает на факт, что полонизмы нами обработанной базы языковых данных можно разбить на группы трех частей речи, т. е. выделяются группы существительных, прилагательных и глаголов. Частеречный аспект иноязычных вкраплений польского происхождения иллюстрирует диаграмма № 2 (см. ниже).

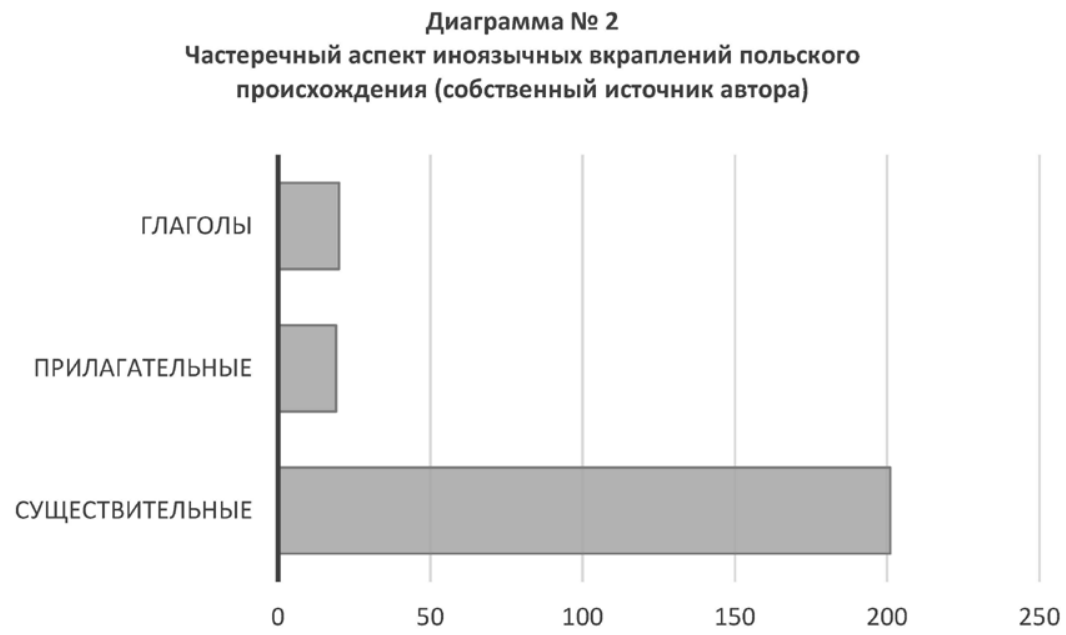

Подавляющее большинство польскоязычных вкраплений образуют существительные, их всего 201 лексическая единица (ср. баранка, календарь, лавр, отвага, пориия, рота, столяр, ффакm, фбартук, иикорий и др.). Сравнительно одинаково количество полонизмов, принадлежащих к группе глаголов и прилагательных. База языковых данных содержит всего 20 глагольных выражений (ср. вербовать, позволить, потраббить, трактовать, шлифовать и др.) и 19 прилагательных (ср. доскональный, паршивый, подлый, пунктуальный, скромный и др.).

Подводя итог представленной выше темы, можно констатировать, что процесс заимствования тесно связан с проблематикой языковых контактов. Лексические единицы языка-источника (языка-посредника), вошедшие в лексику языка-реципиента, принято 
называть заимствованными словами или иноязычными вкраплениями. Относительно иноязычных вкраплений польского языка применяется термин полонизм, представляющий собой заимствование из польского языка. Подытоживая вопрос об иноязычных вкраплениях польского происхождения, необходимо отметить, что полонизмы составляют неотъемлемую часть лексики русского языка. Благодаря взаимным историческим контактам русского и польского языков (политические, экономические, культурные связи), слова, заимствованные из польского языка, можно разделить на две группы. Первую группу составляют полонизмы, относящиеся непосредственно к польскому языку, т. е. польский язык воспринимается в качестве исконного языка-источника (ср. вензель, nан, хоругвь). Вторая группа полонизмов - слова, относящиеся к польскому языку, для которых польский язык выполняет посредническую роль, т. е. выступает в роли языка-посредника (ср. бунт, лектор, panорm). По временному аспекту преобладают в лексике русского языка польскоязычные вкрапления периода XVII-XIX вв., из которых самое большое количество относится именно к XVIII в. (ср. бекеша, забияка, опека). По частеречному аспекту можно утверждать, что подавляющее большинство полонизмов образуют существительные (ср. отвага, столяр, фартук), лишь небольшое количество образовано полонизмами, относящимися к глаголам (ср. позволить, потрафбить, трактовать) и прилагательным (ср. паршивыц̆, пунктуальный, скромныц̆).

\section{FOREIGN LANGUAGE INCLUSIONS OF POLISH ORIGIN IN THE VOCABULARY OF THE RUSSIAN LANGUAGE (GENERAL POSITIONS)}

SUMMARY The article presents the problems of foreign language inclusions of Polish origin, which form an integral part of the vocabulary of the Russian language. Due to the mutual historical contacts of the Russian and Polish languages (political, economic, cultural ties), two types of polonisms are found in the vocabulary of the Russian language. The first group is polonisms that are directly related to the Polish language (the Polish language is perceived as the original source language). The second group is polonisms related to the Polish language, for which the Polish language plays an intermediary role (the Polish language acts as an intermediary language). In terms of the temporal aspect, interspersed with Polish origin of the period of the $17^{\text {th }}-19^{\text {th }}$ centuries prevail in the Russian language vocabulary, of which the largest number refers specifically to the $18^{\text {th }}$ century. From the part of speech aspect, it can be argued that the vast majority of polonisms form nouns, only a small number are formed by polonisms that relate to verbs and adjectives.

\section{ЛИТЕРАТУРА}

I Ахманова О. С., 1966 (2016), Словарь лингвистических терминов, Москва.

I Вех С., 2013, Русские в Царстве Польском во второй половине XIX в. и начале XX в., «Петербургские славянские и балканские исследования», 52/2, с. 198-215. 
I Влахов С. - Флорин С., 1980, Международные отношения, Москва.

I Гадимова Дж. А., 2019, Польские заимствования в русском литературном языке (конец XIX-XX вв.), «Kognitywistyka i Media w Edukacji», 1, c. 98-104.

I Жеребило Т. В., 2010, Словарь лингвистических терминов, Назрань.

I Захватаева К. С., 2010, Языковые контакты: базовые понятия и их стратификация, «Известия РГПУ им. А. И. Гериена», 126, с. 165-170.

I Климова М. В., 2016, Большой этимологический словарь русского языка, Москва.

I Крысин Л. П., 1968, Иноязыцные слова в современном русском языке, Москва.

I Леонтьев А.А., 1966, Иноязычные вкрапления в русскую речь, «Вопросы культуры речи», 7, с. 60-68.

I Норлусенян В.С., 2010, Иноязычные вкрапления: современное состояние проблемы, «Вестник НГУ», 57, с. 63-66.

I Ожегов С. И. - Шведова Н. Ю., 2017, Толковый словарь русского языка, Москва.

I Рогозная Н. Н., 2014, Теоретические основы языковых контактов, «Вестник ИрГТУ», $85 / 2$, c. 306-311.

I Тихонов А. Н. - Хашимов Р. И. (общ. ред.), 2008, Энщиклопедический словарь-справочник лингвистических терминов и понятий. Русский язык, Москва.

IУшаков Д. Н. (ред.), 1935-1940, Толковый словарь русского языка, Москва. https://biblioclub.ru/?page=dict\&dict_id=117. [цит.: 29.12.2019]

I Шанский Н. М., 1964 (2017), Лексикология современного русского языка, Москва.

I Шетэля В., 2017,О польских вкраплениях в русских текстах XIX века (на примере слова повстанец в русском языке), «Известия вузов», 8/1, с. 62-66.

I Tusiewicz, R., 2006, Historia Polski od A do Z, Warszawa. 